\title{
TESTOSTERONE AND THE HEART
}

Travis Goodale, M.D.; Archana Sadhu, M.D.; Steven Petak, M.D., J.D.; Richard Robbins, M.D. Houston Methodist Hospital, Houston, Texas

\begin{abstract}
Testosterone (T) has a number of important effects on the cardiovascular system. In men, $T$ levels begin to decrease after age 40, and this decrease has been associated with an increase in all-cause mortality and cardiovascular (CV) risk. Low T levels in men may increase their risk of developing coronary artery disease (CAD), metabolic syndrome, and type 2 diabetes. Reduced $T$ levels in men with congestive heart failure (CHF) portends a poor prognosis and is associated with increased mortality. Studies have reported a reduced CV risk with higher endogenous $\mathrm{T}$ concentration, improvement of known CV risk factors with $\mathrm{T}$ therapy, and reduced mortality in T-deficient men who underwent T replacement therapy versus untreated men. Testosterone replacement therapy (TRT) has been shown to improve myocardial ischemia in men with CAD, improve exercise capacity in patients with $\mathrm{CHF}$, and improve serum glucose levels, HbA1c, and insulin resistance in men with diabetes and prediabetes. There are no large long-term, placebo-controlled, randomized clinical trials to provide definitive conclusions about TRT and CV risk. However, there currently is no credible evidence that T therapy increases CV risk and substantial evidence that it does not. In fact, existing data suggests that T therapy may offer CV benefits to men.
\end{abstract}

\section{The Endocrinology of Testosterone}

Testosterone ( $\mathrm{T}$ ) is the principal male sex hormone, secreted primarily by the testes and transported in the blood by the carrier protein, sex-hormone binding globulin (SHBG). Only $1 \%$ to $2 \%$ of testosterone circulates in blood as unbound "free" testosterone, but this fraction exhibits the most potent biological activity. Dihydrotestosterone (DHT), the most biologically active androgen, is synthesized from testosterone by $5 \alpha$-reductase and exerts its effects via a family of androgen receptors. Some biological effects of testosterone may result from its aromatization to estradiol and subsequent interaction with the estrogen receptor. In addition to developing primary and secondary sex characteristics, androgens have diverse anabolic functions such as increasing muscle mass and bone density. ${ }^{1}$ Testosterone has also demonstrated a number of important effects on the cardiovascular system. In men, T levels begin to decrease after age 40 , and this decrease has been associated with an increase in all-cause mortality and cardiovascular risk. ${ }^{2,3}$ However, whether low $\mathrm{T}$ causes negative cardiovascular events or is simply associated with them has yet to be determined. ${ }^{4}$ This review highlights the evidence underlying the major interrelationships between androgens and the cardiovascular system.

\section{Testosterone Actions on Cardiovascular Cells}

Testosterone and the more potent DHT bind to cytoplasmic androgen receptors (AR) that are chaperoned by heat shock proteins. Once bound, the DHT-AR complex migrates to the nucleus, dimerizes with another DHT-AR complex, associates with coactivator proteins, and transactivates a family of genes with androgen response elements that alter myocardial and vascular cell behavior. ${ }^{1}$ Evidence also supports a direct rapid membrane effect of $\mathrm{T}$ on G-protein-coupled receptors, with an increase in inositol trisphosphate and diacylglycerol and subsequent alterations in cytoplasmic calcium and potassium channel activity. ${ }^{5}$

\section{Cardiovascular Risk in Testosterone Deficiency Definition}

Testosterone deficiency (TD) is a well-established major medical condition that negatively impacts male sexuality, general health, and quality of life. Symptoms include decreased libido, erectile dysfunction, decreased energy, depressed mood, irritability, and decreased sense of well-being. In the correct clinical setting, the diagnosis of TD is usually confirmed by low serum concentrations of total T (e.g., < $200 \mathrm{ng} / \mathrm{mL}$ ) drawn in the early morning. However, there is no specific value that reliably distinguishes men who experience signs and symptoms of TD from those who do not nor those who will likely respond to treatment. Interpretation of total $\mathrm{T}$ concentrations is confounded by variation between individuals, variation in serum SHBG, and variation in androgen sensitivity. ${ }^{6}$ Furthermore, considerable controversy has arisen regarding the accuracy of currently available commercial testosterone assays, especially those showing T levels at the lower end of the "normal" range. ${ }^{4}$ Free testosterone level may be a more reliable indicator of androgen status, but more studies are needed to confirm this. The prevalence of symptomatic TD ranges from $2.1 \%$ to $12.8 \%$ in middle-aged to older men, with an incidence of 12 new cases/1000 person-years in the United States and Europe. Populations at high risk for TD include men with $\mathrm{CHF}$, type 2 diabetes, obesity, chronic obstructive pulmonary disorder, HIV, and chronic opioid use. ${ }^{7}$

\section{Overall and Cardiovascular Mortality in Testosterone Deficiency}

Low $\mathrm{T}$ levels are also associated with chronic medical conditions such as metabolic syndrome, diabetes, dyslipidemia, hypertension, renal failure, frailty, malignancy, and cardiovascular (CV) events. Several meta-analyses and systematic reviews have clearly associated TD with increased CV disease and mortality. Ruige et al. found that higher $\mathrm{T}$ levels were associated with a decreased risk for CV events in men $>70$ years (HR of 0.84 ; 95\% CI, 0.76-0.92) but not in younger men (HR of $1.01 ; 95 \%$ CI, 0.95-1.08). ${ }^{8}$ In a meta-analysis by Araujo et al. that included 18 studies and more than 22,000 subjects, overall and CV mortality were related to $\mathrm{T}$ levels. The authors concluded that although there was considerable heterogeneity in the studies, low $\mathrm{T}$ levels were significantly associated with overall mortality and strongly $(P=.06)$ associated with $\mathrm{CV}$ mortality. ${ }^{9}$ Finally, Corona et al. screened 1,178 articles and found 70 in their meta-analysis that showed a clear association between 
low T/high estradiol levels and CV disease. ${ }^{10}$ Longitudinal studies demonstrated that overall mortality and CV mortality were highest in those with low $\mathrm{T}$ levels. Whether low $\mathrm{T}$ and increased mortality are simply covariates or a causal relationship remains to be proven.

\section{Testosterone Deficiency and Coronary Artery Disease}

In their 2013 review, Oskui and colleagues reported on evidence suggesting that men with lower levels of endogenous $\mathrm{T}$ are more likely to develop CAD during their lifetimes. ${ }^{11}$ The severity of CAD has also been investigated as a function of serum T concentrations. Four studies have noted an inverse relationship between serum $\mathrm{T}$ levels and CAD severity, ${ }^{6}$ with lower levels of serum T associated with more severe CAD and higher serum $\mathrm{T}$ levels associated with reduced severity. ${ }^{11}$ However, these results should be interpreted with caution due to the relatively small sample size included in each study. Furthermore, the mechanism through which TD may exacerbate CAD is unknown. Additional research is needed to further evaluate the association between low T levels and CAD severity. Testosterone may have several types of action, including direct vasodilatory action, a direct effect on myocardial oxygen consumption, and membrane repolarization..$^{5,11}$

\section{Testosterone Deficiency and Congestive Heart Failure}

Emerging evidence indicates that congestive heart failure $(\mathrm{CHF})$ is more than just a syndrome affecting a failing heart. It is becoming clear that the pathophysiology of CHF involves other pathways as well, including the skeletal muscles and the endocrine system. Jankowska et al. studied 208 men with CHF and 366 healthy male controls. Low T levels were found in all NYHA classes of heart failure. ${ }^{12}$ It has also been shown that reduced $\mathrm{T}$ levels in men with $\mathrm{CHF}$ portends a poor prognosis and is associated with increased mortality. ${ }^{13}$

\section{Testosterone Deficiency and Dyslipidemia}

The evidence regarding the association between baseline $\mathrm{T}$ levels and lipid subfractions is conflicting; therefore, there is no clear consensus among the numerous authors who have investigated this association. No definitive statement can be made regarding the effects of testosterone replacement therapy on the levels of either LDL or HDL cholesterol. ${ }^{11}$

\section{Testosterone Deficiency and Metabolic Syndrome}

Metabolic syndrome (MetS) has been shown to have a close relationship with TD. In a meta-analysis of cross-sectional and prospective observational studies, Brand et al. found an inverse relationship between total T, free T, and SHBG, respectively, and MetS (OR per quartile decrease $=1.7 ; 95 \% \mathrm{CI}, 1.63-1.77)$. The association varied across the individual components of MetS and was strongest with hypertriglyceridemia, abdominal obesity, and hyperglycemia. ${ }^{14}$ It has been well established that men with type 2 diabetes have lower levels of T compared to men without diabetes. ${ }^{11}$ Population-based studies have revealed that men with the lowest quartile of endogenous serum $\mathrm{T}$ concentrations are at double the risk of developing type 2 diabetes and MetS. ${ }^{6}$

\section{Impact of Testosterone Replacement Therapy Overall Mortality in Testosterone Replacement Therapy}

Hypogonadal men have more fat and less muscle. The Hypogonadism in Males study compared 836 hypogonadal men with 1,326 eugonadal men. The mean body mass index (BMI) for hypogonadal men was found to be 31.5 compared to 28.5 for eugonadal men.
The authors also verified that the odds ratio for having hypogonadism was significantly higher in obese men, and there was a statistically significant negative correlation between total $\mathrm{T}$ level and BMI. ${ }^{15}$ Testosterone replacement therapy (TRT) has been shown to decrease fat mass. In their meta-analysis, Corona et al. demonstrated that TRT led to a decrease of $2.19 \%$ in fat mass. ${ }^{16}$

There are no large long-term, placebo-controlled, randomized clinical trials to provide definitive conclusions about TRT and CV risk. However, there is a significant amount of literature from the past several decades that provides valuable information. Many studies have indicated that low serum $\mathrm{T}$ concentrations are associated with increased CV risk and mortality and that TRT may have clinically relevant $\mathrm{CV}$ benefits. ${ }^{6}$

Two recent observational studies reported increased CV risks in men who received testosterone prescriptions. ${ }^{17,18}$ Although they gained a significant amount of media attention, neither study provided credible evidence of increased CV risk. In one study, Vigen et al. made an official correction for misreporting their primary results, which actually showed a lower percentage of adverse CV events in the T-treated group compared to untreated men. ${ }^{19}$ In the other study, Finkle et al. had no control group, so it is unknown whether CV events differed between treated and untreated men with TD. ${ }^{19}$ The U.S. Food and Drug Administration (FDA) reviewed the $C V$ safety of $T$ products shortly after publication of these articles. In its assessment of CV risks and T therapy, the FDA identified a total of only 4 studies suggesting an increased risk, yet none provided solid evidence to support this. By comparison, more than 100 studies have reported reduced CV risk with higher endogenous $\mathrm{T}$ concentration, improvement of known CV risk factors with $\mathrm{T}$ therapy, and reduced mortality in T-deficient men who underwent TRT versus untreated men. ${ }^{19}$ Two recent studies in men who received TRT found reduced CV events in those whose follow-up $\mathrm{T}$ level normalized compared to men whose $\mathrm{T}$ concentration remained low..$^{20,21}$ Another large observational study noted that $\mathrm{T}$ therapy was associated with reduced risk of myocardial infarction in men in the highest risk category. ${ }^{22}$ A recently published meta-analysis of 75 placebo-controlled studies, the largest to date, found no evidence of increased CV risk with T therapy and clear evidence of improved metabolic profiles. ${ }^{23}$ An international expert consensus regarding testosterone deficiency and treatment, published in the July 2016 Mayo Clinic Proceedings, concluded: "There is no credible evidence at this time that $\mathrm{T}$ therapy increases $\mathrm{CV}$ risk and substantial evidence that it does not. Indeed, there is a strong signal that $\mathrm{T}$ therapy may offer CV benefits to men." 19

\section{Coronary Artery Disease and Myocardial Infarction}

Three recent randomized, placebo-controlled trials demonstrated that administration of $\mathrm{T}$ improves myocardial ischemia in men with CAD. All three found that in men with CAD, testosterone prolongs the time to exercise-induced ST-segment depression as measured on treadmill stress testing. ${ }^{24-26}$ Testosterone has been reported to have direct vasodilatory effects on coronary arteries in men with CAD. ${ }^{26}$

\section{Congestive Heart Failure}

Testosterone replacement therapy has been shown to significantly improve exercise capacity without affecting left ventricular ejection fraction (LVEF). Given emerging evidence from basic-science models, it is reasonable to assume that TRT positively affects the exercise capacity of CHF patients via a peripheral mechanism, such as promoting increased type I muscle fiber proliferation. ${ }^{27}$ Four authors have investigated the effects of TRT on exercise capacity in 
men with CHF. Toma et al. performed a meta-analysis of these studies and discovered that there was a net pooled improvement of 0.52 standard deviations in exercise capacity among those who received TRT. The meta-analysis revealed that patients treated with T experienced a $16.7 \%$ increase (equivalent to $\sim 54 \mathrm{~m}$ ) in the 6-minute walk test, a $15.9 \%$ increase in the isometric walk test, and a $22.7 \%$ increase in peak $\mathrm{VO}_{2}$. All four studies included in this meta-analysis evaluated the effects of TRT on LVEF as well. Although T was shown to significantly improve exercise capacity, none of the studies found a significant change in LVEF, although NYHA class was shown to improve in two of the studies. Of the patients in the TRT group, 35\% (20 of 57) experienced an improvement of $\geq 1$ NYHA class in their functional capacity compared to only $9.8 \%$ of patients in the placebo group (5 of 51). No significant adverse CV events were noted. ${ }^{28}$ Further studies are needed to evaluate the clinical effects of TRT in $\mathrm{CHF}$, but testosterone appears to be a promising therapeutic option for patients with CHF. Thus, a large clinical trial would be warranted to determine the value of TRT in this patient group.

\section{Metabolic Syndrome and Diabetes}

Studies indicate that TRT can improve MetS and diabetes by decreasing serum glucose levels, $\mathrm{HbA1c}$, and insulin resistance in men with diabetes and prediabetes. ${ }^{6}$ Four studies in hypogonadal men with MetS or diabetes showed that insulin resistance improved in men who received $\mathrm{T}$ therapy, and fasting glucose and HbA1c were improved in three of the four studies. ${ }^{29-32}$ In patients with type 2 diabetes and TD, Dihndsa et al. demonstrated an increase in insulin sensitivity using a hyperglycemic-euglycemic clamp, an increase in lean body mass using dual energy x-ray absorptiometry, and a decrease in subcutaneous fat using magnetic resonance imaging. In this study, fat biopsies were also used to show that the expression of insulin-signaling genes (IR- 1 , IRS-1, AKT-2, and GLUT 4) was lower in men with TD and diabetes. Treatment with $\mathrm{T}$ upregulated these genes, thereby providing a molecular explanation for observed clinical changes. ${ }^{33}$

\section{Other Side Effects and Risks of Testosterone Replacement Therapy \\ Prostate Cancer}

In 2005, Calof et al. published a meta-analysis of 19 randomized placebo-controlled trials that included 651 men who received TRT and 433 men who received placebo. They reported two major differences between the groups. The TRT group had a significantly greater incidence of all prostate-related adverse events, with a pooled odds ratio of 1.78 (95\% CI, 1.07-2.95). Combined prostate events included all instances of prostate biopsies, prostate cancer, prostate-specific antigen (PSA) $>4 \mathrm{ng} / \mathrm{mL}$ or a $1.5-\mathrm{ng} / \mathrm{mL}$ increase in PSA during the study period, increased International Prostate Symptom Score, and acute urinary frequency. However, none of the individual prostate-related adverse events significantly differed between groups, including incident prostate cancer, which showed no difference between the TRT group and placebo. ${ }^{34}$ In 2016, Boyle et al. reported results of a meta-analysis on prostate cancer in TRT trials. They concluded that TRT for hypogonadism does not appear to increase PSA or the risk of prostate cancer. The summary relative risk of prostate cancer in TRT patients was 0.87 (95\% CI, 0.30-2.50). ${ }^{35}$

\section{Polycythemia}

Calof et al. also found a significant (> 50\%) increase in hematocrit in the TRT group - the most common adverse effect noted in that group, with a pooled odds ratio of 3.69 (95\% CI, 1.82- 7.51). Among the subjects with elevated hematocrit, there was only one incident of serious complication (cerebral hemorrhage). ${ }^{34}$ The most recent meta-analysis examining the adverse effects of TRT was performed by Fernandez-Balsells et al. in 2010. The eligibility criteria for this analysis included all placebo-controlled studies that enrolled men (1) with low or low-normal testosterone levels, and (2) who received any testosterone formulation for $\geq 3$ months. Similar to the previous reports, TRT resulted in a significant increase in hemoglobin levels. ${ }^{36}$

\section{Thromboembolic Events}

In a double-blinded, randomized, placebo-controlled trial of TRT in 46 men with CAD, no adverse change in coagulation factors was found.$^{37}$ In general, higher levels of $\mathrm{T}$ are not associated with an increased risk of venous thrombosis or pulmonary embolism. ${ }^{38}$ Ramasamy et al. found no increase in thrombotic events in a cohort of hypogonadal men on TRT compared to a comparable group of men not on TRT, all of whom were followed for more than 3 years. ${ }^{39}$

\section{Summary and Conclusions}

It is clear that testosterone is an active hormone in many aspects of cardiovascular health, and TD is clearly associated with poor cardiovascular outcomes. However, the effect of TRT remains unclear at this time. The U.S. FDA recommends that all T supplements carry a warning that they may increase the risk of heart attack and stroke. Many authors of systematic reviews on the CV risks of TRT call for a large randomized multicenter trial on this issue. In a comprehensive overview of systematic reviews to date, Onasanya and colleagues from the Johns Hopkins School of Public Heath concluded that currently available data regarding an association between TRT and CV events are conflicted. ${ }^{40}$ At this time, a detailed discussion with patients about the risks and benefits of TRT is essential until further data is available.

\section{Key Points:}

- There is no credible evidence at this time that testosterone therapy increases cardiovascular risk, but there is substantial evidence that it does not.

- Many studies have indicated that low serum T concentrations are associated with increased cardiovascular risk and mortality and that testosterone replacement therapy may have clinically relevant cardiovascular benefits.

- Studies have reported reduced CV risk with higher endogenous testosterone concentration, improvement of known $\mathrm{CV}$ risk factors with $\mathrm{T}$ therapy, and reduced mortality in testosterone-deficient men who underwent testosterone replacement therapy versus untreated men.

- Testosterone replacement therapy has been shown to: o improve myocardial ischemia in men with CAD o improve exercise capacity in men with $\mathrm{CHF}$

o improve serum glucose levels, HbA1c, and insulin resistance in men with diabetes and prediabetes

Conflict of Interest Disclosure: The authors have completed and submitted the Methodist DeBakey Cardiovascular Journal Conflict of Interest Statement and none were reported.

Keywords: testosterone, dihydrotestosterone, androgen, testosterone deficiency, testosterone replacement therapy

\section{References}

1. Matsumoto AM, Bremner WJ. Testicular Disorders. In: Melmed S, Polonsky KS, Larsen PR, Kronenberg HM, editors. Williams 
Textbook of endocrinology, 13th ed. New York: Elsevier Health Sciences; (C2015. p. 688-777.

2. Kloner RA, Carson C 3rd, Dobs A, Kopecky S, Mohler ER 3rd. Testosterone and Cardiovascular Disease. J Am Coll Cardiol. 2016 Feb 9;67(5):545-57.

3. Oskui PM, French WJ, Herring MJ, Mayeda GS, Burstein S, Kloner RA. Testosterone and the cardiovascular system: a comprehensive review of the clinical literature. J Am Heart Assoc. 2013 Nov 15;2(6):e000272.

4. Herati AS, Cengiz C, Lamb DJ. Assays of Serum Testosterone. Urol Clin North Am. 2016 May;43(2):177-84.

5. Er F, Michels G, Brandt MC, et al. Impact of testosterone on cardiac L-type calcium channels and Ca2+ sparks: acute actions antagonize chronic effects. Cell Calcium. 2007 May;41(5):46777.

6. Morgentaler A, Miner MM, Caliber M, Guay AT, Khera M, Traish AM. Testosterone therapy and cardiovascular risk: advances and controversies. Mayo Clin Proc. 2015 Feb;90(2):224-51.

7. Zarotsky V, Huang MY, Carman W, et al. Systematic literature review of the epidemiology of nongenetic forms of hypogonadism in adult males. J Hormones. 2014 Jul 22;2014:190347.

8. Ruige JB, Mahmoud AM, De Bacquer D, Kaufman JM. Endogenous testosterone and cardiovascular disease in healthy men: a meta-analysis. Heart. 2011 Jun;97(11):870-5.

9. Araujo AB, Dixon JM, Suarez EA, Murad MH, Guey LT, Wittert GA. Clinical review: Endogenous testosterone and mortality in men: a systematic review and meta-analysis. J Clin Endocrinol Metab. 2011 Oct;96(10):3007-19.

10. Corona G, Rastrelli G, Monami M, et al. Hypogonadism as a risk factor for cardiovascular mortality in men: a meta-analytic study. Eur J Endocrinol. 2011 Nov;165(5):687-701.

11. Oskui PM, French WJ, Herring MJ, Mayeda GS, Burstein S, Kloner RA. Testosterone and the cardiovascular system: a comprehensive review of the clinical literature. J Am Heart Assoc. 2013 Nov 15;2(6):e000272.

12. Jankowska EA, Biel B, Majda J, et al. Anabolic deficiency in men with chronic heart failure: prevalence and detrimental impact on survival. Circulation. 2006 Oct 24;114(17):1829-37.

13. Wehr E, Pilz S, Boehm BO, März W, Grammer T, Obermayer-Pietsch B. Low free testosterone is associated with heart failure mortality in older men referred for coronary angiography. Eur $\mathrm{J}$ Heart Fail. 2011 May;13(5):482-8.

14. Brand JS, Rovers MM, Yeap BB, et al. Testosterone, sex hormone-binding globulin and the metabolic syndrome in men: an individual participant data meta-analysis of observational studies. PLoS One. 2014 Jul 14;9(7):e100409.

15. Mulligan T, Frick MF, Zuraw QC, Stemhagen A, McWhirter C. Prevalence of hypogonadism in males aged at least 45 years: the HIM study. Int J Clin Pract. 2006 Jul;60(7):762-9.

16. Corona G, Monami M, Rastrelli G, et al. Testosterone and metabolic syndrome: a meta-analysis study. J Sex Med. 2011 Jan;8(1):272-83.

17. Vigen R, O'Donnell Cl, Barón AE, et al. Association of testosterone therapy with mortality, myocardial infarction, and stroke in men with low testosterone levels. JAMA. 2013 Nov 6;310(17):1829-36.

18. Finkle WD, Greenland S, Ridgeway GK, et al, Increased risk of non-fatal myocardial infarction following testosterone therapy prescription in men. PLoS One. 2014 Jan 29;9(1):e85805.

19. Morgentaler A, Zitzmann M, Traish AM, et al. Fundamental Concepts Regarding Testosterone Deficiency and Treatment: Inter- national Expert Consensus Resolutions. Mayo Clin Proc. 2016 Jul;:91(7):881-96.

20. Sharma R, Oni OA, Gupta K, et al. Normalization of testosterone level is associated with reduced incidence of myocardial infarction and mortality in men. Eur Heart J. 2015 Oct 21;36(40):270615.

21. Anderson JL, May HT, Lappé DL, et al. Impact of Testosterone Replacement Therapy on Myocardial Infarction, Stroke, and Death in Men With Low Testosterone Concentrations in an Integrated Health Care System. Am J Cardiol. 2016 Mar 1;117(5):794-9.

22. Baillargeon J, Urban RJ, Kuo YF, et al. Risk of Myocardial Infarction in Older Men Receiving Testosterone Therapy. Ann Pharmacother. 2014 Sep;48(9):1138-44.

23. Corona G, Maseroli E, Rastrelli G, et al. Cardiovascular risk associated with testosterone-boosting medications: a systematic review and meta-analysis. Expert Opin Drug Saf. 2014 Oct;13(10):1327-51.

24. English KM, Steeds RP, Jones TH, Diver MJ, Channer KS. Low-dose transdermal testosterone therapy improves angina threshold in men with chronic stable angina: A randomized, double-blind, placebo-controlled study. Circulation. 2000 Oct 17;102(16):1906-11.

25. Rosano GM, Leonardo F, Pagnotta P, et al. Acute anti-ischemic effect of testosterone in men with coronary artery disease. Circulation. 1999 Apr 6;99(13):1666-70.

26. Webb CM, Adamson DL, de Zeigler D, Collins P. Effect of acute testosterone on myocardial ischemia in men with coronary artery disease. Am J Cardiol. 1999 Feb 1;83(3):437-9, A9.

27. Dos Santos MR, Sayegh AL, Bacurau AV, et al. Effect of Exercise Training and Testosterone Replacement on Skeletal Muscle Wasting in Patients With Heart Failure With Testosterone Deficiency. Mayo Clin Proc. 2016 May;91(5):575-86.

28. Toma M, McAlister FA, Coglianese EE, et al. Testosterone supplementation in heart failure: a meta-analysis. Circ Heart Fail. 2012 May 1;5(3):315-21.

29. Sonmez A, Taslipinar A, Tapan S, Serdar MA. Comment on: Jones et al. Testosterone replacement in hypogonadal men with type 2 diabetes and/or metabolic syndrome (the TIMES2 Study). Diabetes Care 2011;34:828-837. Diabetes Care. 2011 Nov;34(11):e172; author's reply e173.

30. Heufelder AE, Saad F, Bunck MC, Gooren L. Fifty-two-week treatment with diet and exercise plus transdermal testosterone reverses the metabolic syndrome and improves glycemic control in men with newly diagnosed type 2 diabetes and subnormal plasma testosterone. J Androl. 2009 NovDec;30(6):726-33.

31. Kapoor D, Goodwin E, Channer KS, Jones TH. Testosterone replacement therapy improves insulin resistance, glycaemic control, visceral adiposity and hypercholesterolaemia in hypogonadal men with type 2 diabetes. Eur J Endocrinol. 2006 Jun;154(6):899-906.

32. Kalinchenko SY, Tishova YA, Mskhalaya GJ, Gooren LJ, Giltay EJ, Saad F. Effects of testosterone supplementation on markers of the metabolic syndrome and inflammation in hypogonadal men with the metabolic syndrome: the double-blinded placebo-controlled Moscow study. Clin Endocrinol (Oxf). 2010 Nov;73(5):602-12.

33. Dhindsa S, Ghanim H, Batra M, et al. Insulin Resistance and Inflammation in Hypogonadotropic Hypogonadism and Their Reduction After Testosterone Replacement in Men With Type 2 Diabetes. Diabetes Care. 2016 Jan;39(1):82-91. 
34. Calof OM, Singh AB, Lee ML, et al. Adverse events associated with testosterone replacement in middle-aged and older men: a meta-analysis of randomized, placebo-controlled trials. J Gerontol A Biol Sci Med Sci. 2005 Nov;60(11):1451-7.

35. Boyle P, Koechlin A, Bota M, et al. Endogenous and exogenous testosterone and the risk of prostate cancer and increased prostate-specific antigen (PSA) level: a meta-analysis. BJU Int. 2016 Nov;118(5):731-41.

36. Fernández-Balsells MM, Murad MH, Lane M, et al. Clinical review 1: Adverse effects of testosterone therapy in adult men: a systematic review and meta-analysis. J Clin Endocrinol Metab. 2010 Jun;95(6):2560-75.

37. Smith AM, English KM, Malkin CJ, Jones RD, Jones TH, Channer KS. Testosterone does not adversely affect fibrinogen or tissue plasminogen activator (tPA) and plasminogen activator inhibitor-1 (PAl-1) levels in 46 men with chronic stable angina. Eur J Endocrinol. 2005 Feb;152(2):285-91.

38. Holmegard HN, Nordestgaard BG, Schnohr P, Tybjaerg-Hansen A, Benn M. Endogenous sex hormones and risk of venous thromboembolism in women and men. J Thromb Haemost. 2014;12(3):297-305.

39. Ramasamy R, Scovell J, Mederos M, Ren R, Jain L, Lipshultz L. Association Between Testosterone Supplementation Therapy and Thrombotic Events in Elderly Men. Urology. 2015 Aug;86(2):283-5.

40. Onasanya O, lyer G, Lucas E, Lin D, Singh S, Alexander GC. Association between exogenous testosterone and cardiovascular events: an overview of systematic reviews. Lancet Diabetes Endocrinol. 2016 Nov;4(11):943-56. 